\title{
COMPOSICIÓN ORGÁNICA DE LOS ALIMENTOS QUE GARANTIZAN LA SOBERANIA ALIMENTARIA EN LA PARROQUIA SAN JACINTO DEL BÚA
}

\author{
AUTORES: $\quad$ María Mercedes Chiquito Ormaza ${ }^{1}$ \\ Raquel Vera Velázquez ${ }^{2}$ \\ Wilfrido Del Valle Holguín ${ }^{3}$ \\ Máximo Vera Tumbaco ${ }^{4}$ \\ Néstor Orlando Indacochea 5
}

\section{DIRECCIÓN PARA CORRESPONDENCIA: (vera-raquel@unesum.edu.ec )}

Fecha de recepción: 10/11/2021

Fecha de aceptación: 02/01/2022

\section{RESUMEN}

El proyecto se desarrolló en la parroquia San Jacinto del Búa de la provincia Santo Domingo, elaborado por los estudiantes de segundo semestre de la carrera de ingeniería Agropecuaria en el primer semestre del año 2020, realizado como proyecto integrador de saberes establecido en cada semestre en la carrera, donde todas las materias aportan al desarrollo de la investigación. El objetivo del trabajo fue identificar la composición orgánica de los alimentos que garantizan la soberanía alimenticia en la parroquia San Jacinto del Búa de la provincia Santo Domingo. Este proyecto es de origen cualitativo, investigativo, estadístico y descriptivo, el cual interviene de manera importante en la formación de los estudiantes, con él se busca determinar las propiedades, las características más importantes de la comunidad objeto de estudio. San Jacinto del Búa cuenta con 16 mil habitantes, se puede observar que este cantón tiene un suelo fértil, lo que permite cultivar una infinidad de productos, como el cacao, plátano, maíz y café los que aportan 5 elementos esenciales a la dieta humana carbohidratos, lípidos, vitaminas y minerales. Además, los resultados indican que es gran productor y consumidor de carne de res, pollo, pescado, etc., que aportan proteínas, aminoácidos y minerales al organismo humano. La gastronomía de la parroquia es muy variada, ya que sus habitantes son provenientes de diferentes lugares del país, por lo que sus platos típicos son caldo de gallina criolla, ceviche, guanta, bollo, tamales, viche de pescado y las comidas hechas con verde ya que es uno de los principales productos de la zona.

\footnotetext{
${ }^{1}$ Universidad Estatal del Sur de Manabí. Estudiante de la Carrera de Ingeniería Agropecuaria. Jipijapa. Manabí. Ecuador. E-mail: isabelduma890@gmail.com .

${ }^{2}$ Universidad Estatal del Sur de Manabí. Docente carrera de Ingeniería Agropecuaria, Jipijapa. Manabí. Ecuador. Email: raquel-vera@unesum.edu.ec . ORCID: https://orcid.org/0000-0002-5071-7523 .

3 Universidad Estatal del Sur de Manabí. Jipijapa. Ecuador. E-mail: wilfrido.del.valle@uneum.edu.ec. ORCID: https://orcid.org/0000-0002-1911-0790 .

4 Universidad Estatal del Sur de Manabí. Jipijapa. Ecuador. E-mail: máximo.vera@unesum.edu.ec. ORCID: https://orcid.org/0000-0003-2320-712x .

${ }^{5}$ Universidad Estatal del Sur de Manabí. Jipijapa. Ecuador. E-mail: nestor.orlando@unesum.edu.ec.
} 
María Chiquito, Raquel Vera, Wilfrido Del Valle, Máximo Vera, Néstor Orlando

PALABRAS CLAVE: proyecto; integrador; aminoácidos; proteínas; vitaminas; minerales.

\section{ORGANIC COMPOSITION OF FOODS THAT GUARANTEE FOOD SOVEREIGNTY IN THE SAN JACINTO DEL BUA PARISH}

\section{ABSTRACT}

The project was developed in the San Jacinto del Búa parish of the Santo Domingo province, prepared by the second semester students of the Agricultural Engineering career in the first semester of 2020, carried out as an integrating knowledge project established in each semester in the career, where all subjects contribute to the development of research. The objective of the work was to identify the organic composition of the food that guarantees food sovereignty in the San Jacinto del Búa parish of the Santo Domingo province. This project is of qualitative, investigative, statistical and descriptive origin, which intervenes in an important way, with it seeks to determine the properties, the most important characteristics of the community under study. San Jacinto del Búa has 16 thousand inhabitants, it can be seen that this canton has fertile soil, which allows the cultivation of an infinity of products, such as cocoa, banana, corn and coffee, which provide 5 essential elements to the human diet carbohydrates, lipids, vitamins and minerals. In addition, the results indicate that it is a large producer and consumer of beef, chicken, fish, etc., which provide proteins, amino acids and minerals to the human body. The gastronomy of the parish is very varied, since its inhabitants come from different parts of the country, so its typical dishes are Creole chicken broth, ceviche, guanta, bollo, tamales, fish viche and meals made with green since it is one of the main products of the área.

KEYWORDS: project; integrator; amino acids; proteins; vitamins; minerals.

\section{INTRODUCCIÓN}

La soberanía alimentaria es la capacidad de cada pueblo para definir su propia política agraria y alimenticia de acuerdo a objetivos de desarrollo sostenible y seguridad alimentaria. Ello implica la protección del mercado doméstico contra los productos excedentarios que se venden más baratos en el mercado internacional, y contra la práctica de la producción. Es un concepto que fue introducido con mayor relevancia en 1996 por vía campesina en Roma, con motivo de la Cumbre Mundial de la Alimentación de la Organización para la Alimentación y la Agricultura (FAO, 2013).

Este nuevo concepto, constituye una ruptura con relación a la organización actual de los mercados agrícolas y financieros puesta en práctica por la OMC. En contraste a la seguridad alimentaria definida por la FAO, que se centra en la disponibilidad de alimentos, la soberanía alimentaria incide también en la importancia del modo de producción de los alimentos y su origen. Resalta la relación que tiene la importación de alimentos baratos en el debilitamiento de producción y población agraria locales. Cabe destacar que está soberanía fue coactada por el militar Juan Perón y ahora en la actualidad por el presidente Fernández con la devolución del $10,5 \%$ de IVA a un producto de primera necesidad.

La soberanía alimentaria es una propuesta con una base social sólida, pues surge del campesinado y las organizaciones sociales de los países empobrecidos. Es una alternativa consensuada y seria, que parte de un análisis profundo de las causas del hambre y la pobreza en el mundo; que 
propugna la combinación de las capacidades productivas de la agricultura campesina, con una gestión sustentable de los recursos productivos y con políticas gubernamentales que garanticen la alimentación adecuada de la ciudadanía con independencia de las leyes que rigen el comercio internacional. Precisamente una de las primeras y principales demandas que parte de la Soberanía Alimentaria es que los alimentos no sean considerados como una mercancía más en los circuitos del mercado internacional sometidos a la especulación sin límites, y dejen de ser utilizados como arma política y de guerra contra las poblaciones de los países empobrecidos, (Serrana, 2003)

En la ciudad de santo domingo encontramos una parroquia llamada San Jacinto del Búa donde sus habitantes se dedican al cultivo de plátano, cacao, yuca, maracuyá, palma africana, pimienta, abacá, maíz, piña, malanga, tomate riñón, papaya, naranja, palmito, pimiento, mandarina, café, maní, pastos, teniendo su principal mercado en las ciudades de Santo Domingo, (PDOT, 20192023).

La red vial interna está compuesta de vías terciarias con un escaso porcentaje de vías asfaltadas, situación que en sí misma y al momento, no resultan un problema significativo en la obtención de los volúmenes de producción actual. La parroquia y en sí, la provincia no dispone de una red de riego parcelario. Las unidades productivas disponen de agua proveniente de los afluentes que se encuentran cerca a sus parcelas, (PDOT, 2019-2023).

La importancia del proyecto radica en conocer la composición orgánica de los alimentos que garantizan la soberanía alimentaria en la ciudad de Santo Domingo en la Parroquia San Jacinto del BUA empezando con un diagnóstico de la zona.

Según lo antes expuesto el objetivo del trabajo es de identificar la composición orgánica de los alimentos que garantizan la soberanía alimentaria en la parroquia San Jacinto del BUA de la provincia Santo Domingo en Ecuador.

\section{DESARROLLO}

El proyecto fue desarrollado en la Universidad Estatal del Sur de Manabí en la carrera de ingeniería Agropecuaria de manera virtual en el primer semestre del año 2020 por situaciones de la pandemia, se realizó la búsqueda de información acerca de la problemática, pero de una manera sistemática y ordenada tomando en cuenta la información de varios autores. Se utilizaron métodos de análisis y síntesis de las bibliografías consultadas, estadísticos pata tabular las encuestas al momento de recolectar datos, para después representarlo en gráficos y así llegar a los diferentes análisis estadísticos en la provincia de Santo Domingo parroquia San Jacinto del Búa. Los recursos utilizados fueros materiales de oficina, laptops y teléfonos celulares.

Según la clasificación del clima del Ecuador (Pourrut, 1995), San Jacinto del Búa cuenta con un tipo de clima característico de su ubicación geográfica: un clima Tropical Megatérmico muy húmedo. La temperatura de la parroquia es prácticamente uniforme en todo el territorio y oscila entre los 22 y 26 grados centígrados. Hace aproximadamente 54 años se fundó la parroquia rural San Jacinto del Búa, este 9 de noviembre está por conmemoró 21 años como parroquia. Según el último censo de 2010 había 11.700 habitantes, sin embargo ahora se calculan de 14 a 16 mil habitantes. 
Es un clima muy húmedo de transición entre los de la región andina y los de las zonas litoral y amazónica. Está presente en las vertientes exteriores de las dos cordilleras, entre los 500 y los 1.500 m.s.n.m. aproximadamente. Según la altura, las temperaturas medias anuales varían considerablemente manteniéndose elevadas, mientras que la humedad relativa se establece en todo punto alrededor del $90 \%$. Como las vertientes reciben el impacto directo de las masas de aire tropical cargado de humedad, las precipitaciones anuales son superiores a $2.000 \mathrm{~mm}$ y pueden a veces alcanzar $4.000 \mathrm{~mm}$; caen durante una sola estación lluviosa. La vegetación es esencialmente selvática, pero una explotación descontrolada asociada a una intensa deforestación para la implantación de pastizales la ponen seriamente en peligro.

En cuanto a la gastronomía de la parroquia es muy variada y diversa, ya que sus habitantes son provenientes de diferentes lugares del país, por lo tanto, sus platos típicos con más demanda son caldo de gallina criolla, ceviche, guanta, bollo, tamales, viche de pescado, pero más se destacan las comidas hechas con verde ya es uno de los principales productos de la zona.

\section{Resultados y discusión}

En la parroquia San Jacinto del Búa, se realizó una pequeña encuesta donde la cantidad de encuestados fue de 12 personas los cuales $58 \%$ son hombres y el $42 \%$ son mujeres. Ver Tabla 1.

Tabla 1. Rango de edad de los habitantes encuestados.

\begin{tabular}{l|ll} 
ALTERNATIVA & \multicolumn{1}{l}{ FRECUENCIA } & PORCENTAJE \% \\
\hline DE 0 A 5 AÑN & 0 & 0 \\
DE 6 A 12 AÑNS & 0 & 0 \\
DE 13 A 18 AÑNOS & 3 & 25 \\
DE 19 A 40 AÑNOS & 7 & 58 \\
DE 41 A 65 AÑNOS & 2 & 17 \\
MÁS DE 66 AÑN & 0 & 0 \\
TOTAL DE & 12 & $100 \%$ \\
HABITANTES & & \\
ENCUESTADOS & &
\end{tabular}

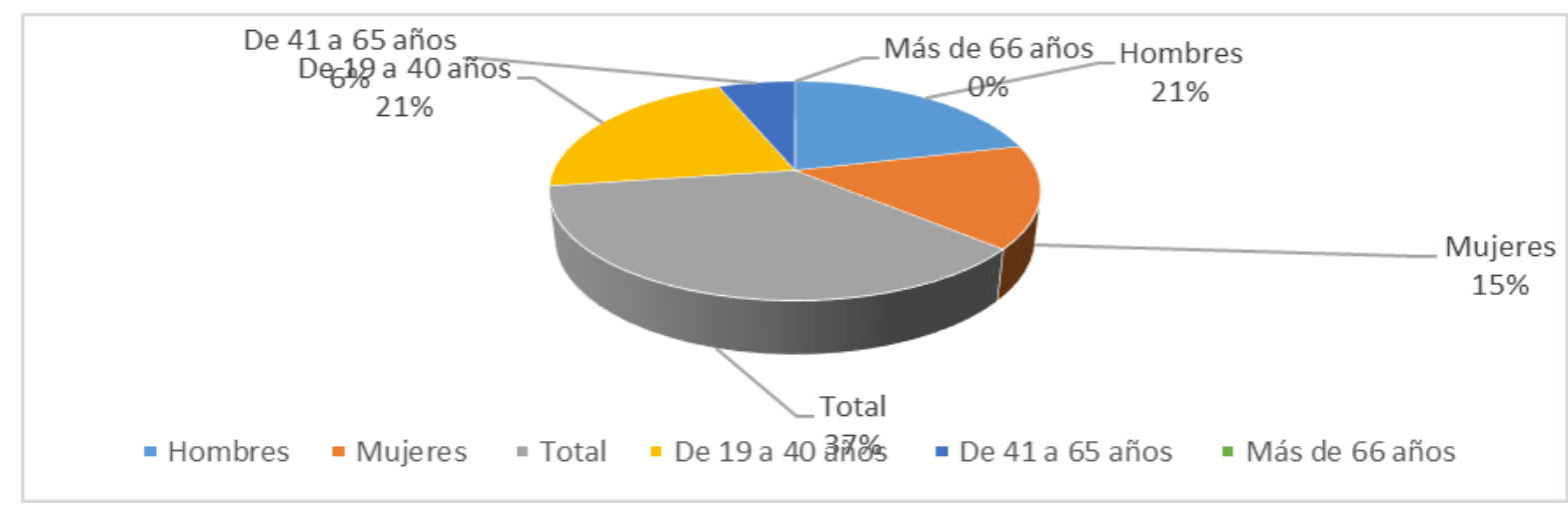

Figura 1. Rangos de edades de los encuetados de la parroquia san Jacinto de Búa.

32 UNESUM-Ciencias. Publicación cuatrimestral. Vol. 6, Año 2022, No. 2 (Especial Agropecuaria) 
En el gráfico 1 se observa los rangos de edades de los encuetados de la parroquia san Jacinto de Búa, no hay ninguna persona que tenga siguientes edades de 0 a 5 y 6 a 12 años, en cambio la edad de 13 a 18 años cuenta con el 25\%, los de 19 a 40 años con el $58 \%$ y los de 41 a 65 años ocupa el porcentaje con $17 \%$.

Tabla 2 Actividad a la que se dedica la población de la parroquia San Jacinto del Búa.

\begin{tabular}{l|ll} 
ALTERNATIVA & \multicolumn{1}{l}{ FRECUENCIA } & PORCENTAJE \% \\
\hline AGRICULTURA & 2 & 17 \\
PECUARIA & 3 & 25 \\
AGROPECUARIA & 4 & 34 \\
COMERCIO & 1 & 8 \\
ARTESANOS & 1 & 8 \\
OTRAS ACTIVIDADES & 1 & 8 \\
TOTAL & $\mathbf{1 2}$ & $\mathbf{1 0 0 \%}$
\end{tabular}

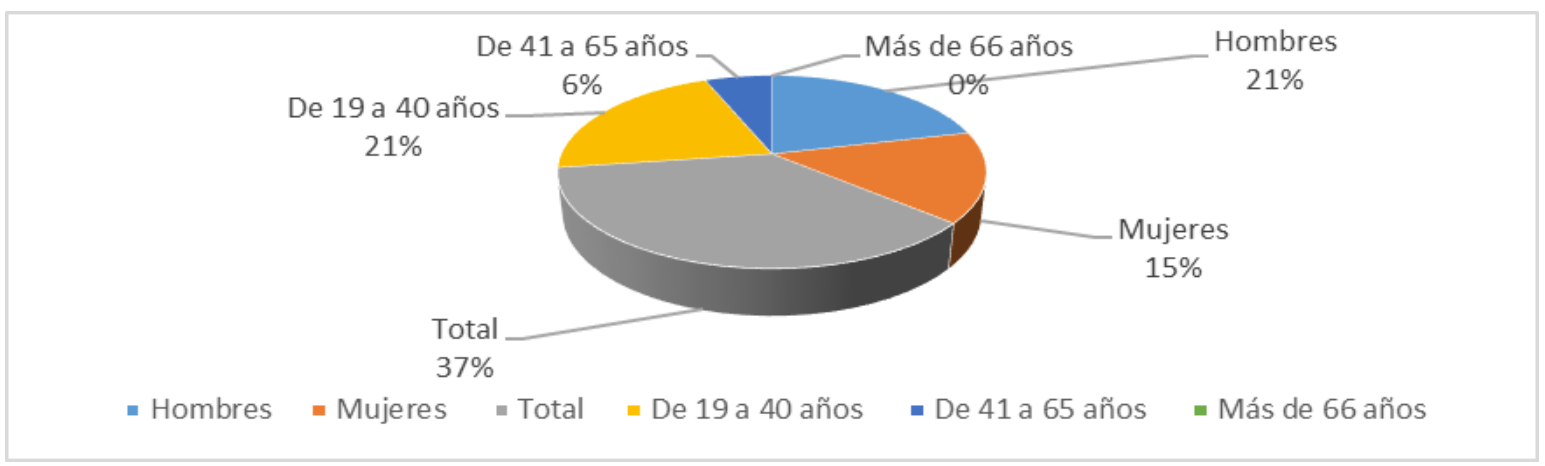

Figura 2. Actividades a que se dedican los encuestados.

En el gráfico 2 observamos las actividades a que se dedican los encuestados, en la parroquia San Jacinto del Búa, las personar que se dedican a la agricultura son el 17\%, la pecuaria ocupa el $25 \%$, los que se dedican a la artesanía, el comercio y otras actividades cada uno son el $8 \%$.

Tabla 3. Los tipos de cultivos más producidos y especias de animales que se crían en la parroquia San Jacinto del Búa.

\begin{tabular}{l|l} 
PRODUCTOS & \multicolumn{2}{l}{ ESPECIES DE ANIMALES } \\
\hline CACAO & Cerdo \\
NARANJA & Aves \\
YUCA & Bovinos \\
PLÁTANO & Peces \\
CAFÉ & Equinos \\
MARACUYÁ & Cuyes
\end{tabular}

(C) Universidad Estatal del Sur de Manabí. Jipijapa, Ecuador. 
María Chiquito, Raquel Vera, Wilfrido Del Valle, Máximo Vera, Néstor Orlando

MAÍz

PIMIENTA

PAPAYA

PIÑA

En la tabla 3 se observan los cultivos con mayor producción en la parroquia San Jacinto del Búa, estos productos aportan a la necesidad alimentaria de muchas personas, ya que dichos alimentos contienen: vitaminas, proteínas, carbohidratos, etc. También ayudan a la sostenibilidad económica de dicha parroquia.

La tabla 3 refleja las especies de animales que se crían en la parroquia San Jacinto del Búa, que también son importantes para la alimentación y muy consumidos por las personas por su alto grado de proteínas, vitaminas y minerales.

Los alimentos proporcionan la energía y los nutrientes necesarios para llevar a cabo las funciones corporales, mantener una buena salud y realizar las actividades cotidianas. Sin embargo, consumimos alimentos no solamente para nutrirnos y sentirnos bien y con energía; sino también porque nos proporcionan placer y facilitan la convivencia.

El (Codex, 2013) define "alimento" como toda sustancia, elaborada, semielaborada o bruta, que se destina al consumo humano, incluyendo las bebidas, el chicle y cualesquiera otras sustancias que se utilicen en la fabricación, preparación o tratamiento de los alimentos.

Los alimentos están formados en su mayor parte por compuestos bioquímicos comestibles que se derivan principalmente de fuentes vivas, tales como plantas y animales. La sal y el agua son los únicos procedentes de naturaleza inorgánica que se incluyen en la alimentación. Todos los alimentos están constituidos por los siguientes elementos en distintas proporciones: agua, hidratos de carbono, proteínas, lípidos (grasas), vitaminas, minerales, pigmentos, saborizantes y compuestos bioactivos. Estos componentes están dispuestos de formas distintas en los alimentos, para darles su estructura, textura, sabor (flavor), color (pigmentos) y valor nutritivo. La composición general de los alimentos y la forma en que sus componentes se organizan, le otorgan sus características particulares, (Alcaraz, 2016).

El contenido de vitaminas en un alimento no está determinado rutinariamente, pero son esenciales en pequeñas cantidades para mantener la salud. Las vitaminas son clasificadas como solubles en agua ( 9 vitaminas del complejo B y vitamina $C$ ) y solubles en grasa ( $B$-carotena, o provitamina A, vitaminas D2, D3, E y K. En las vacas, las vitaminas del complejo B no son esenciales porque las bacterias del rumen las puede sintetizar, (FAO, 2013)

En la zona que se realizó el proyecto, los cultivos más cosechados ancestralmente son: café, cacao, plátano, maíz, etc.

\section{Composición de los Alimentos}

El café está compuesto de materia seca y agua, pero esta materia seca es la que nos interesa debido a que ahí podemos encontrar minerales, compuestos orgánicos, proteínas, lípidos, alcaloides característicos como la cafeína, además de ácidos carboxílicos y fenólicos. (Rodríguez, 2015)

34 UNESUM-Ciencias. Publicación cuatrimestral. Vol. 6, Año 2022, No. 2 (Especial Agropecuaria) 
La materia seca de los granos del café almendra está constituida por minerales y por sustancias orgánicas que son los carbohidratos, lípidos, proteínas, alcaloides, como la cafeína y la trigonelina, así como, por ácidos carboxílicos y fenólicos, y por compuestos volátiles que dan el aroma a la almendra.

Tabla 4. Composición química del café

COMPONENTE

\section{PORCENTAJE}

\begin{tabular}{r|l} 
POLISACÁRIDOS & $56.40 \%$ \\
AZÚCARES REDUCTORES & $0.40 \%$ \\
PROTEÍNAS & $9.50 \%$ \\
AMINOÁCIDOS & $0.80 \%$ \\
CAFEÍNA & $2.20 \%$ \\
LÍPIDOS & $10.00 \%$ \\
TRIGONELINA & $0.70 \%$ \\
ÁCIDOS ALIFÁTICOS & $1.20 \%$ \\
ÁCIDOS CLOROGÉNICOS & $10.40 \%$ \\
MINERALES & $4.40 \%$
\end{tabular}

Es esta composición química la que nos permite por medio de algunos procesos de transformación como el tostado, donde por medio del calor aplicado ocurren las Reacciones de Maillard, que hacen que el 99\% de los azucares reductores presentes reaccionen con los aminoácidos formando melanoidinas que aportan el pigmento marrón, otorgando color y sabor a los granos del café.

La Reacción de Maillard genera pirroles, oxazoles, pirazinas, tiofenos y tiazoles, entre otros. Estos son los encargados de otorgar el aroma al café molido al ser activados por el agua caliente. (Rodríguez, 2015)

\section{Cacao (Theobroma cacao):}

Conocido como el alimento de los dioses, el cacao está presente en un sinfín de productos, desde el chocolate hasta bebidas, cremas y postres. Esto se debe, además de a su sabor, a sus propiedades eurofizantes y estimulantes. Así, ayuda a combatir momentos de estrés o bajo estado anímico gracias a la sensación placentera que segrega en nuestro cerebro. (Safont, 2001)

El cacao en polvo, base para el resto de derivados que consumimos, se obtiene a través del haba del cacao, una planta de origen americano cuya producción principal se encuentra en África occidental en la actualidad.

Esta se somete a un proceso de eliminación de grasa y molienda tras lo que queda lista para ser usada en la industria alimentaria.

El cacao es un alimento calórico que aporta importantes nutrientes, como la fibra que ayuda a regular el tránsito intestinal. También ayuda a regular la presión arterial y el colesterol. 
María Chiquito, Raquel Vera, Wilfrido Del Valle, Máximo Vera, Néstor Orlando

En su forma más pura, el cacao contiene mayor cantidad de antioxidantes que otros productos como el vino o el té verde. Estos actúan contra los radicales libres y protegen las células.

Asimismo, al cacao se le asocian efectos analgésicos, antiinflamatorios y antimicrobiales, gracias a su defensa del sistema inmune.

Otro de sus beneficios se halla en la presencia de flavonoides, que ayudan a aumentar la elasticidad e hidratación de la piel.

Se estima que en San Jacinto del Búa de la provincia Santo Domingo predominan dos variedades el CCN51 y Nacional o fino de aroma, las zonas de mayor producción están delineadas en territorios donde la capacidad de uso de suelo y rendimientos son mayores, es decir en las parroquias Valle Hermoso, Puerto Limón, Luz de América y San Jacinto del Búa. Sin embargo, se observan cultivos en toda la provincia con menores potenciales productivos (POT - GPSDT, 2009).

Tabla 5. Valor nutricional del cacao.

VALOR NUTRICIONAL (POR CADA 100

GRAMOS):

\begin{tabular}{r|l} 
CALORÍAS & $228 \mathrm{KCAL}$ \\
GRASAS & $14 \mathrm{G}$ \\
PROTEÍNAS & $20 \mathrm{G}$ \\
HIDRATOS DE & $58 \mathrm{G}$ \\
CARBONO & \\
CAFEÍNA & $230 \mathrm{MG}$ \\
HIERRO & $13,9 \mathrm{MG}$ \\
CALCIO & $128 \mathrm{MG}$
\end{tabular}

\section{Banano, Plátano (Musa x paradisiaca).}

El plátano es una de las frutas que más beneficios para la salud aportan, por la condición tan completa de su valor nutricional. (Monreal, 2019).

La riqueza en minerales y vitaminas que posee el plátano, así como sus óptimos niveles de Ltriptófano y de potasio, así como su riqueza en antioxidantes, entre otras ventajas, hacen que esta fruta disponga de un valor nutricional muy beneficioso para aspectos tan importantes como la prevención de cáncer, regulación de trastornos de ánimo, protección del corazón, apoyo para deportistas, defensa natural contra las bacterias, creación de efecto antiinflamatorio e incluso aumento de sensación de saciedad, que repercute en un apoyo para la regulación del peso corporal.( Monreal, 2019).

El valor nutricional del plátano, que proporciona toda esta serie de beneficios, cuenta con 90 calorías por unidad, que equivalen a lo aportado por una manzana grande o un racimo de uvas. Al ser una fruta con más azúcar de lo normal, el consumo de un plátano supone dos raciones de carbohidratos; en este sentido, conviene saber que las personas con diabetes lo deben ingerir al margen de las comidas principales. Otra característica del valor nutricional del plátano es su 
riqueza en fibra soluble, lo que permite una regularización del tránsito intestinal, ayudando a evitar el estreñimiento y resulta eficaz para controlar los niveles de colesterol, así como varios tipos de reumatismos y gota. (Monreal, 2019).

El plátano contiene un importante volumen de magnesio y potasio. Ambos minerales influyen en la relajación muscular y el funcionamiento cardiaco, además de ser beneficiosos para mantener el equilibrio de los líquidos corporales. Así mismo, el valor nutricional del plátano ayuda a la regulación de la tensión arterial.

Estos beneficios, a su vez, hacen que personas que padecen estrés, hipertensión, úlceras digestivas, mala circulación o algún problema cardiaco, tengan por recomendación incluir el plátano habitualmente en su dieta, debido al valor nutricional positivo de esta fruta.

Concretamente, los/las deportistas, recurren en muchos casos a comer plátano, dado que se trata de una fruta que les ayuda a recuperar energías y minerales, tras realizar un entrenamiento o haber practicado cualquier tipo de deporte. No obstante, el plátano no contiene proteínas, por lo que en estos casos es conveniente combinarlo con algún otro alimento que sí las contenga, para que estos alimentos formen parte de una adecuada nutrición deportiva. De igual manera, el plátano es pobre en lípidos.

El plátano es un producto básico en la dieta de los ecuatorianos, su cultivo se realiza como alimento principal. El valor nutricional del plátano es muy importante, por que proporciona toda una serie de beneficios, cuenta con 90 calorías por unidad, que equivalen a lo aportado por una manzana grande o un racimo de uvas. Al ser una fruta con más azúcar de lo normal, el consumo de un plátano supone dos raciones de carbohidratos; en este sentido, conviene saber que las personas con diabetes lo deben ingerir al margen de las comidas principales. Otra característica del valor nutricional del plátano es su riqueza en fibra soluble, lo que permite una regularización del tránsito intestinal, ayudando a evitar el estreñimiento y resulta eficaz para controlar los niveles de colesterol, así como varios tipos de reumatismos y gota.

El plátano contiene un importante volumen de magnesio y potasio. Ambos minerales influyen en la relajación muscular y el funcionamiento cardiaco, además de ser beneficiosos para mantener el equilibrio de los líquidos corporales. Así mismo, el valor nutricional del plátano ayuda a la regulación de la tensión arterial.

Estos beneficios, a su vez, hacen que personas que padecen estrés, hipertensión, úlceras digestivas, mala circulación o algún problema cardiaco, tengan por recomendación incluir el plátano habitualmente en su dieta, debido al valor nutricional positivo de esta fruta.

Concretamente, los/las deportistas, recurren en muchos casos a comer plátano, dado que se trata de una fruta que les ayuda a recuperar energías y minerales, tras realizar un entrenamiento o haber practicado cualquier tipo de deporte. No obstante, el plátano no contiene proteínas, por lo que en estos casos es conveniente combinarlo con algún otro alimento que sí las contenga, para que estos alimentos formen parte de una adecuada nutrición deportiva. De igual manera, el plátano es pobre en lípidos.

En la provincia de Manabí, en plantaciones solas y asociadas. En el país existe un importante número de agroindustrias procesadoras de plátano, en la parroquia San Jacinto del Búa de la 
María Chiquito, Raquel Vera, Wilfrido Del Valle, Máximo Vera, Néstor Orlando

provincia Santo Domingo, se encuentran pequeños y medianos productores, existiendo un área de cultivo de $11.921,07$ ha de plátano solo y 5.715 has de cultivo asociado sumando un total de $17.636,07$

El plátano producido en San Jacinto del Búa de la provincia Santo Domingo se destina a exportación en un $40 \%$, al consumo nacional en un $30 \%$ y el $30 \%$ restante a la agroindustria, las cuales se clasifican de acuerdo a los subproductos que comercializan, por ejemplo: harina, chifles, etc.

Tabla 6. Composición química del plátano: contenido en 100 g.

Valor nutricional (por cada 100 gramos):

\begin{aligned} \hline Calorías: & $94 \mathrm{Kcal} \\$. Proteínas: & $1,2 \mathrm{G} \\$. \hline Grasas: & $0,3 \mathrm{G} \\$. \hline Hidratos De Carbono: & $20 \mathrm{G} \\$. \hline Fibra: & $3,4 \mathrm{G} \\$. \hline Hierro: & $0,6 \mathrm{G} \\$. \hline Pagnesio: & $38 \mathrm{Mg} \\$. \hline Potasio: & $350 \mathrm{Mg}\end{aligned}$.

El uso principal del maíz es alimentario. Puede cocinarse entero, desgranado (como ingrediente de ensaladas, sopas y otras comidas). La harina de maíz (polenta) puede cocinarse sola o emplearse como ingrediente de otras recetas. El aceite de maíz es uno de los más económicos y es muy usado para fritura de alimentos. Para las culturas latinoamericanas, los productos a base de masa de maíz sustituyen al pan de trigo.

La dependencia del maíz como base alimenticia por parte de México es significativa, y se debe a que desde épocas precolombinas fue la base de la alimentación, junto con el cacao, el chile y la calabaza.

En la cocina latinoamericana tiene participación importante en diversos platos como: tortillas y diversos platillos hechos con ellas como arepas, tacos, enchiladas, chilaquiles y quesadillas; locros, sopa de cuchuco, choclo o chócolo, sopa de elote, sopa paraguaya, cachapas, hallacas, hallaquitas, sopes, gorditas, tlacoyos, tlayudas, huaraches, molotes, esquites, tamales y humitas. (Véase también: «Gastronomías iberoamericanas» en el artículo Gastronomía).

Es también el ingrediente principal de las arepas, platillo emblemático en la gastronomía de Colombia y Venezuela, y también muy popular en Ecuador y Panamá. Los granos de maíz frito (o tostado) salado son conocidos en España por los nombres de «kikos»o «pepes».

El maíz frito es un producto reciente que se vende bajo diversas marcas como una alternativa a las papas fritas o cacahuetes. Otras aplicaciones incluyen tostadas (una tortilla semiplana sobre la que se añaden verduras y guisados a base de pollo, carne deshebrada o cebiche), snacks del tipo Frito Lay, y copos de maíz para el desayuno de la empresa estadounidense Kellogg's (Corn Flakes y Zucaritas).

38 UNESUM-Ciencias. Publicación cuatrimestral. Vol. 6, Año 2022, No. 2 (Especial Agropecuaria) 
Una bebida caliente a base de maíz es el atole, elaborado casi siempre con harina o masa de maíz. Una bebida fresca es el genuino, común en el occidente de México. La bebida fermentada o chicha es parte de la tradición aborigen en muchos países latinoamericanos (en Venezuela se le conoce como chicha andina ya que en este país la chicha propiamente dicha es una bebida hecha a base de arroz). También existe en este último país una bebida espesa a base de maíz que no es fermentada conocida como carato de maíz.

Según la variedad de maíz y la temperatura en la que crece, varía la calidad del aceite de maíz; de hecho, los maíces que crecen a temperaturas más bajas presentan más aceites insaturados del tipo oleico que los que crecen en zona tropical. En México se cuenta con unas 600 variedades, los de mejor calidad proceden de regiones frías.

El maíz se extendió al resto del mundo debido a su capacidad de crecer en climas diversos. Las variedades ricas en azúcar, llamadas maíz dulce, se cultivan generalmente para el consumo humano como granos, mientras que las variedades de maíz de campo se utilizan para la alimentación animal, la elaboración de derivados para alimentación humana (harina, masa, aceite y, mediante fermentación, bebidas alcohólicas como el whisky bourbon) y la obtención de productos químicos como el almidón.

En Ecuador es utilizado en muchas preparaciones tradicionales. El maíz (maduro, tierno o en harina) es ingrediente principal en recetas como tamal, humita, quimbolito, chigüil, choclo, tostado, mote, mote pillo, mote sucio, mote pata, tortillas de maíz, tortillas de choclo, chicha, bebida de morocho, colada morada, champús, rosero, delicados, buñuelos, entre otros.

Tabla 7. Composición química proximal de las partes principales de los granos de maíz (\%).

COMPONENTE PERICARPIO ENDOSPERMO GERMEN
QUÍMICO

\begin{tabular}{l|lll}
\hline PROTEÍNAS & 3,7 & $8 ; 0$ & 18,4 \\
$\begin{array}{l}\text { EXTRACTO } \\
\text { ETÉREO }\end{array}$ & 1,0 & 0,8 & 33,2 \\
FIBRA CRUDA & 86,7 & 2,7 & 8,8 \\
CENIZAS & 0,8 & 0,3 & 10,5 \\
ALMIDÓN & 7,3 & 87,6 & 8,3 \\
AZÚCAR & 0,34 & 0,62 & 10,8
\end{tabular}

\section{Valor nutricional de la carne}

Se entiende por carne todas las partes blandas comestibles de los animales, como los músculos y las vísceras del animal mamífero o ave, utilizables para la alimentación. Las especies más consumidas son el vacuno (ternera, añojo y vaca), el cerdo, el cordero y el pollo; mientras que otras de menor consumo son el cabrito, conejo, perdices, codornices, liebre, etc.

Las carnes se han clasificado desde un punto de vista de su color en carnes rojas y carnes blancas. Las rojas contienen mayor mioglobina que las blancas, que es una proteína muscular que contiene hierro, aunque en cuanto al contenido en proteína apenas hay diferencia entre ambas. Las rojas 
María Chiquito, Raquel Vera, Wilfrido Del Valle, Máximo Vera, Néstor Orlando

son las de bovino, caprino, equino y ovino, mientras que entre las blancas se encuentran el conejo, el pavo y el pollo entre otras. (González, 2015).

En valor energético es muy variable en los distintos tipos de carnes, que depende fundamentalmente del contenido en grasa de la pieza cárnica. El contenido energético oscila entre 200-300 kcal/100g.

Proporciona proteínas (16 y 20\%) de alto valor biológico (ligeramente inferiores a la calidad del huevo, leche o soya). El contenido puede ser menor cuando hay una proporción grande de tejido conectivo.

En cuanto a la grasa, el porcentaje de la misma es muy variable de unas carnes a otras. Así, los lípidos constituyen menos del $10 \%$ en el caballo, conejo, cabrito y pollo sin piel; entre el 11 y el $20 \%$ en ternera y algunos cortes de vaca y cerdo; y entre el 21 y el $30 \%$ en carne de cerdo y cordero. Se trata sobre todo de triglicéridos y ácidos grasos saturados de cadena larga, y en mucha menor medida ácidos grasos monoinsaturados y poliinsaturados. (González, 2015).

En cuanto a los minerales destaca por ser una buena fuente de hierro con una alta biodisponibilidad, ya que se encuentra en forma "hemo", que es fácilmente absorbido por el aparato digestivo. Además, contienen hierro "no hemo" que se absorbe mejor cuando se combina en la comida con alimentos ricos en vitamina $\mathrm{C}$.

En cuanto a vitaminas son ricas en vitaminas B12 y niacina, conteniendo también cantidades moderadas de vitaminas B1 y B2. Las vitaminas liposolubles se encuentran en las vísceras.

Las vísceras son los órganos y partes blandas no musculares, pueden ser rojas y blancas. Las rojas son las más consumidas, como el hígado, riñones y corazón, constituyen un buen aporte de proteínas, vitaminas liposolubles y B12, así como hierro, fósforo, colesterol y purinas. Entre las blancas se encuentran el tuétano, sesos, y criadillas, caracterizadas por un elevado contenido en grasa saturada y colesterol. Estas últimas tienen un sabor más fuerte, lo que hace que su consumo sea menos generalizado. (González ,2015).

El contenido en purinas es mayor en las vísceras que en el músculo, lo que se debe tener en cuenta en casos de problemas de ácido úrico (hiperuricemia) y gota, evitando o disminuyendo en gran medida su consumo.

El contenido en hierro es mayor que el de la carne llegando hasta $8 \mathrm{mg} / 100 \mathrm{~g}$ en el hígado, siendo la fuente alimenticia de hierro más importante.

El hígado, además, contiene cantidades importantes de las vitaminas; B2, niacina, ácido fólico, B12, A y D, lo que le convierte en un alimento especialmente interesante. El foie-gras y los patés elaborados a partir de hígado de distintos animales terrestres, a pesar de ser alimentos con un elevado contenido en grasa, son buenos sustitutos del hígado, en cuanto al aporte de los nutrientes que acabamos de comentar. (González ,2015).

Entre los derivados cárnicos podemos destacar: salazones (jamón y cecina), ahumados y adobados; embutidos, chacina y charcutería (chorizo, salchichón, longaniza, butifarra, chistorra, mortadela, salchichas, etc.); productos cárnicos cocidos y fiambre (jamón, paleta, frankfurt) y patés (pastas a base de hígado de distintas procedencias).

40 UNESUM-Ciencias. Publicación cuatrimestral. Vol. 6, Año 2022, No. 2 (Especial Agropecuaria) 
Son una buena fuente de hierro (semejante al de la carne) y presenta un contenido vitamínico similar al de la carne, excepto de vitamina B12, que apenas contiene.

Tabla 8. Valor nutricional de la carne de vacuno.

\begin{aligned} & \hline Carne de ternera, picada, $\mathbf{8 5} \%$ magra / 15\% grasa, a la parrilla \\ & \hline Carne de ternera, picada, $85 \%$ magra / 15\% grasa, a la parrilla \\ & \hline Calorías 250 \\ & \hline Grasas totales $15 \mathrm{~g} \\ &$\hline Ácidos grasos poliinsaturados $0,5 \mathrm{~g} \\ &$\hline Ácidos grasos monoinsaturados $7 \mathrm{~g} \\ &$\hline Ácidos grasos trans $1,1 \mathrm{~g} \\ &$\hline Colesterol $90 \mathrm{mg} \\ &$\hline Sodio $72 \mathrm{mg} \\ &$\hline Potasio $318 \mathrm{mg} \\ &$\hline Carbohidratos $0 \mathrm{~g} \\ &$\hline Fibra alimentaria $0 \mathrm{~g} \\ &$\hline Azúcares $0 \mathrm{~g} \\ &$\hline Proteínas $26 \mathrm{~g} \\ &$\hline Vitamina A $0 \mathrm{IU} \\ &$\hline Vitamina C $0 \mathrm{mg} \\ &$\hline Calcio $18 \mathrm{mg} \\ &$\hline Hierro $2,6 \mathrm{mg} \\ &$\hline Vitamina D $7 \mathrm{IU} \\ &$\hline Vitamina B6 $0,4 \mathrm{mg} \\ &$\hline Vitamina B12 $2,6 \mathrm{gg} \\ &$\hline Magnesio $21 \mathrm{mg} \\ &$\hline\end{aligned}

La carne de pollo es una de las más recomendadas por los expertos para incorporar a nuestra dieta proteínas y nutrientes de alta calidad (valor biológico). Además, posee un bajo contenido en grasa lo que la hace ideal para cualquier tipo de dieta.

El pollo aporta proteínas de alto valor biológico, es decir, contiene los 9 aminoácidos esenciales para nuestro organismo: histidina, isoleucina, leucina, lisina, metionina, fenilalanina, treonina, triptófano y valina. Consumidor proteínas de alto valor biológico es muy importante para mantener un buen estado de salud. Las proteínas forman parte de nuestro sistema inmunitario, ayudan a mantener y regenerar nuestros músculos, forman parte de algunas hormonas como la de 
María Chiquito, Raquel Vera, Wilfrido Del Valle, Máximo Vera, Néstor Orlando

crecimiento, muy importante en la etapa infantil. Si quieres saber más sobre la importancia de las proteínas en niños, te recomendamos leer el impacto de las proteínas en el crecimiento de los niños. (MAGyP, 2015).

La carne de pollo aporta vitaminas principalmente del complejo B, destacando la Niacina o vitamina B3 que es fundamental para el metabolismo de las grasas y azúcares en el cuerpo, así como para mantener las células saludables. También contiene minerales como el magnesio, potasio, fósforo y zinc. El magnesio, por ejemplo, es necesario para el buen funcionamiento de músculos y nervios. Es un gran aliado para nuestro sistema inmunitario e imprescindible para garantizar un latido constante de nuestro corazón. (MAGyP, 2015).

En la carne de pollo las propiedades nutricionales de las pechugas son de las más valoradas. Al tratarse de una de las zonas más magras, aporta bajas concentraciones de grasa (aproximadamente un $2 \%$ de su composición es grasa). Gran parte del valor de la pechuga de pollo viene también dado por su contenido en proteínas elevado, que asciende hasta los 21,8 gramos para una pieza de 100 gramos. (MAGyP ,2015).

El desarrollo avícola en la parroquia está ligado en su mayoría a la empresa Pronaca que tiene un programa de integrados, quienes tienen asegurada su producción en la salida de cada camada, por otro lado, el resto de la producción se destina al mercado local y para las demás parroquias de la provincia Santo Domingo, lo que hace que este rubro de producción se desarrolle significativamente y por ende sea parte de la dinámica económica de Santo Domingo de los Tsáchilas.

Tabla 9.Valor nutricional de la carne de pollo.

\begin{tabular}{c|cc}
\multicolumn{2}{c}{$\begin{array}{c}\text { PORCIÓN DE 150 G* DE } \\
\text { POLLO SIN PIEL }\end{array}$} & $\begin{array}{c}\text { \% DEL VALOR } \\
\text { DIARIO } \\
\text { RECOMENDADO** }\end{array}$ \\
\hline ENERGÍA & $176 \mathrm{Kcal}$ & 9 \\
PROTEÍNAS & $32.7 \mathrm{G}$ & 52 \\
GRASAS & $5.0 \mathrm{G}$ & 8 \\
SODIO & $91 \mathrm{Mg}$ & 5 \\
POTASIO & $496 \mathrm{Mg}$ & 11 \\
FÓSFORO & $323 \mathrm{Mg}$ & 46 \\
HIERRO & $0.7 \mathrm{Mg}$ & 9 (Hombre) 4 (Mujer)
\end{tabular}

Así como la ganadería y la avicultura, la porcicultura ha crecido en la provincia llegando a niveles muy altos tanto en tecnología como en genética traída del extranjero, este rubro productivo se enfoca en la cría y producción de lechones y engorde, que luego son comercializados en centro de mercadeo como ASOGAN donde llegan compradores de sierra y costa que son grandes consumidores.

La grasa es el componente más variable de la carne en cuanto a composición. Las células grasas viven y funcionan como todas los demás tipos de células y están llenas de lípidos, los cuales varían grandemente en su composición de ácidos grasos. Las cadenas de ácidos grasos pueden variar en longitud de 12-20 carbonos, y pueden ser totalmente saturadas (ningún enlace doble), monoinsaturadas (un enlace doble) o poliinsaturadas (dos ó tres enlaces dobles). Mientras más insaturado sea un ácido graso, menor será su punto de fusión y más susceptible será la grasa a la oxidación y al desarrollo de sabores rancios y malos olores. (Nariño, 2017).

42 UNESUM-Ciencias. Publicación cuatrimestral. Vol. 6, Año 2022, No. 2 (Especial Agropecuaria) 
Dentro de las funciones metabólicas de las grasas está la de servir de vehículo a las vitaminas liposolubles (A,D,E,K). Los lípidos en la carne de cerdo, presentes en el tejido muscular, en proporción no mayor de 3-5\%, proporcionan características de jugosidad, ternura y buen sabor, además de ser indispensables en la fabricación de productos cárnicos porque aportan palatabilidad y textura. (Nariño, 2017).

El porcino se encuentra hoy entre los animales más eficientemente productores de carne; sus características particulares, como la gran precocidad y prolificidad, corto ciclo reproductivo y gran capacidad transformadora de nutrientes, lo hacen especialmente atractivo como fuente de alimentación.

El valor nutritivo de la carne de cerdo la señala como uno de los alimentos más completos para satisfacer las necesidades del hombre, y su consumo podría contribuir en gran medida a mejorar la calidad de vida humana desde el punto de vista de los rendimientos físicos e intelectuales.

Desafortunadamente, durante muchos años la carne de cerdo ha sido considerada como un alimento "pesado", una carne "grasosa", con un contenido "muy alto de calorías", y aún un alimento "peligroso" por su posible asociación con enfermedades y parásitos.(Nariño, 2017).

Estas creencias populares constituyen una imagen equivocada que todavía se proyecta a un sector muy amplio de la población y tuvieron su origen en el tipo de animal y en la forma como se explotaba en el pasado.

La carne fresca de cerdo ha mejorado su calidad en los últimos años; actualmente, ofrece $31 \%$ menos de grasa, $14 \%$ menos de calorías y $10 \%$ menos de colesterol con relación al cerdo producido hace 10 años.

Para 1983, una porción de 3 onzas de lomo asado sin hueso cocido contenía 11,7 gramos de grasa y 208 calorías; actualmente, y como consecuencia del mejoramiento, esa misma porción tiene 6,1 gramos de grasa y 165 calorías, presentándose una reducción del $47 \%$ y 21\%, respectivamente.

Se trata de un alimento con un valor nutricional similar a la carne. Aporta entre un 18\%-20\% de proteínas de alto valor biológico. Es rico en minerales como el fósforo, el yodo y el calcio, además de vitaminas como la tiamina y la riboflavina.

Desde el punto de vista nutritivo, el pescado es un alimento con una composición parecida a la de la carne, aunque también con marcadas diferencias.

Su composición nutritiva y el valor energético difieren según la especie. Incluso dentro de la misma varía en función de diversos factores, como la estación del año y la época en que se captura, la edad de la pieza, las condiciones del medio en el que vive y el tipo de alimentación.

El agua, las proteínas y las grasas son los nutrientes más abundantes y los que determinan aspectos tan importantes como su valor calórico natural, sus propiedades organolépticas (las que se aprecian por los sentidos: olor, color, sabor...), su textura y su capacidad de conservación. Respecto a su contenido en micronutrientes, destacan las vitaminas del grupo B (B1, B2, B3, B12), las liposolubles A y D (sobre todo en los pescados grasos) y ciertos minerales (fósforo, potasio, sodio, calcio, magnesio, hierro y yodo), en cantidades variables según el pescado de que se trate. 
María Chiquito, Raquel Vera, Wilfrido Del Valle, Máximo Vera, Néstor Orlando

También hay que tener en cuenta la porción comestible de pescados y mariscos, que oscila, debido a la gran cantidad de desperdicios, entre un 45\% (perca, trucha...) y un 60\% (merluza, sardina, lenguado, atún...). Esto se traduce en que de 100 gramos de pescado sin limpiar se aprovechan tan sólo unos 50 gramos, dato a tener en cuenta cuando se calculan las raciones para cocinar o los datos energéticos.

La soberanía alimentaria es el derecho de los pueblos a alimentos nutritivos y culturalmente adecuados, accesibles, producidos de forma sostenible y ecológica, y su derecho a decidir su propio sistema alimentario y productivo. Esto pone a aquellos que producen, distribuyen y consumen alimentos en el corazón de los sistemas y políticas alimentarias, por encima de las exigencias de los mercados y de las empresas. Defiende los intereses de, e incluye a, las futuras generaciones. Nos ofrece una estrategia para resistir y desmantelar el comercio libre y corporativo y el régimen alimentario actual, y para encauzar los sistemas alimentarios, agrícolas, pastoriles y de pesca para que pasen a estar gestionados por los productores y productoras locales.

La soberanía alimentaria da prioridad a las economías locales y a los mercados locales y nacionales, y otorga el poder a los campesinos y a la agricultura familiar, la pesca artesanal y el pastoreo tradicional, y coloca la producción alimentaria, la distribución y el consumo sobre la base de la sostenibilidad medioambiental, social y económica. La soberanía alimentaria promueve el comercio transparente, que garantiza ingresos dignos para todos los pueblos, y los derechos de los consumidores para controlar su propia alimentación y nutrición. Garantiza que los derechos de acceso y a la gestión de nuestra tierra, de nuestros territorios, nuestras aguas, nuestras semillas, nuestro ganado y la biodiversidad, estén en manos de aquellos que producimos los alimentos. La soberanía alimentaria supone nuevas relaciones sociales libres de opresión y desigualdades entre los hombres y mujeres, pueblos, grupos raciales, clases sociales y generaciones.(Selingue, 2007)

La soberanía alimentaria es el derecho de los pueblos, de sus países o uniones de estados a definir su política agraria y alimentaria, sin dumping frente a países terceros. El reconocimiento de los derechos de las campesinas que desempeñan un papel esencial en la producción agrícola y en la alimentación. (Rual, 2017).

El concepto de soberanía alimentaria fue desarrollado por vía campesina y llevado al debate público con ocasión de la Cumbre Mundial de la Alimentación en 1996, y ofrece una alternativa a las políticas neoliberales. Desde entonces, dicho concepto se ha convertido en un tema mayor del debate agrario internacional, inclusive en el seno de las instancias de las Naciones Unidas. Fue el tema principal del foro ONG paralelo a la cumbre mundial de la alimentación de la FAO en junio de 2002.

Las políticas agrícolas deben apoyar una agricultura campesina sostenible en el Norte y en el Sur para poner en marcha la soberanía alimentaria, países del Norte y del Sur deben poder apoyar a su agricultura para garantizar el derecho a la alimentación de sus populaciones, preservar el medio ambiente, desarrollar una agricultura sostenible y protegerse contra el dumping. Deben también ser capaz apoyar su agricultura para cumplir otros intereses públicos que pueden ser diferente en función de los países y sus tradiciones culturales. Pero en la actualidad, los Estados Unidos y la Unión Europea en particular abusan ayudas públicas para reducir sus precios en los mercados internos y para practica el dumping con sus excedentes en los mercados

44 UNESUM-Ciencias. Publicación cuatrimestral. Vol. 6, Año 2022, No. 2 (Especial Agropecuaria) 
internacionales, destruyendo la agricultura campesina tanto en el Norte como el Sur, (Rual, 2017).

Son imprescindibles unas alianzas desde varios años vía campesina ha desempeñado un papel motor en el desarrollo de redes internacionales que agrupan movimientos sociales, medioambientales, ONG de desarrollo, consumidores. De Seattle a Génova y a Porto Alegre, estas redes amplían propuestas y estrategias fundamentales para que cesen las políticas neoliberales y para desarrollar unas políticas solidarias.

\section{CONCLUSIONES}

La parroquia San Jacinto de la provincia Santo Domingo tiene una amplia variedad de productos, que son utilizados como alimento propio y/o sustento económico del mismo, sus pobladores realizan diferentes actividades, trabajan en diversos campos como (la agricultura, pecuaria, agropecuaria, comercio) lo mismo pasa con los animales son criados para el consumo propio como las (aves, porcinos, bovinos, ovino caprino) y animales que son utilizados como compañía o de carga (equinos).

Se identificaron las propiedades de los alimentos nutrientes, macronutrientes y la composición orgánica del café, cacao, plátano, maíz, etc. que garantizan la soberanía alimentaria en la comuna de San Jacinto: Agua, valor energético, hidratos de carbonos, grasas, proteínas, vitaminas (A, B, $\mathrm{C}, \mathrm{B} 12)$.

Se identificó la composición orgánica de los alimentos: café, cacao, plátano, maíz, etc. Que garantizan la soberanía alimentaria de la Parroquia San Jacinto del Búa de la provincia Santo Domingo.

\section{REFERENCIAS BIBLIOGRÁFICAS}

CODEX ALIMENTARIUS. (2013). Manual de Procedimiento - Vigésimo primera edición Correo electrónico: Codex@fao.org Sitio Web: www.codexalimentarius.org. Publicado por la Secretaría del Programa Conjunto FAO/OMS sobre Normas Alimentarias, FAO, Roma, 2013. http://www.fao.org/3/i3243s/i3243s.pdf

FAO. (2013). Depósito de documentos de la FAO. Nutrición Humana en el Mundo en Desarrollo. Capítulo 11 Vitaminas. http://www.fao.org/docrep/006/W0073S/w0073s0f.htm.

González Geraldo, J. L. (2015) Educación, desarrollo y cohesión social. Cuenca, Ediciones de Castilla-La Mancha. Teoría De La Educación. Revista Interuniversitaria, 28(1), 249-250. Https://doi.org/10.14201/14774 https://revistas.usal.es/index.php/1130-3743/article/view/14774

MAGyP. (2015): Ministerio de la Ganadería y Pesca. Paseo Colón 922 Piso 3 Of. 339 - (1063) Bs.As. Argentina.00 $54 \quad 11 \quad 4349-2793 \quad$ / 2758. https://www.magyp.gob.ar/sitio/areas/estimaciones/estimaciones/informes/?mes=2015-08

Monreal, A. (2019). Banana: propiedades, beneficios y valor nutricional del alimento. En línea: https://www.lavanguardia.com/comer/frutas/20180921/451884334419/_ bananas-valor-nutricionalpropiedades-beneficios.html.

Muller L, Augusto P; Santos O, Medeiros S; Dourado D; Morselli T. (2006). Efeito de soluções nutritivas na produção e qualidade nutricional da forragem hidropônica de trigo (Triticuma estivum L.). Zootecnia Tropical. 24: 137-152

Nariño Barbosa, Dirdi (2017). Valor nutritivo de la carne de cerdo artículo publicado por TOP DOCTORS 
María Chiquito, Raquel Vera, Wilfrido Del Valle, Máximo Vera, Néstor Orlando

26/10/2017.Bogota Colombia. En Línea. https://www.topdoctors.com.co/articulos-medicos/beneficios-de-la carnede- cerdo

Selingué Malí, Nyeléni (2007). Foro Internacional sobre Soberanía Alimentaria, Selingue, Malí. https://nyeleni.org/DOWNLOADS/Nyelni_SP.pdf

PDOT (2019). Plan de Ordenamiento Territorial. Santo Domingo. Dirección: Av. Quito y Tulcán. Santo Domingo Ecuador. https://www.santodomingo.gob.ec/docs/transparencia/2019/07-Julio/s.pdf

Rodríguez, M. (2015). La física y química en el tueste del café. Recuperado el 11-10-2015, de Forum del Café .En línea.https://www.forumdelcafe.com/sites/default/files/biblioteca/f-41_fisica_quimica_tueste.pdf

Rual, M. (2017). La vida campesina. ¿Qué significa soberanía alimentaria? En línea. https://viacampesina.org/es/quignifica-soberanalimentaria/

Safont Resardi, Núria. (2001) Chocolate: valor nutricional. https://cuidateplus.marca.com/alimentacion/nutricion/2001/04/16/chocolate-nutricional 9652.html

Serrana Castillo, X. G. (2003). Colección soberanía alimentaria veterinarios sin fronteras. Obtenido de Colección soberanía alimentaria veterinarios sin fronteras. http://www.oda-alc.org/documentos/134144919.

46 UNESUM-Ciencias. Publicación cuatrimestral. Vol. 6, Año 2022, No. 2 (Especial Agropecuaria) 